\title{
O ORIENTADOR EDUCACIONAL NO BRASIL
}

\author{
Miriam Pascoal* \\ Eliane Costa Honorato** \\ Fabiana Aparecida de Albuquerque***
}

\begin{abstract}
RESUMO: Historicamente, a orientação educacional tem sido uma das funções exercidas pelo profissional da educação denominado pedagogo. Nos diferentes estados brasileiros e nas diferentes redes escolares, este profissional, se existente, recebe denominações variadas e exerce atividades também variadas. Tal diversidade descaracteriza a real dimensão de seu fazer profissional e estabelece um conflito entre os diversos papéis desempenhados pelos diferentes profissionais da educação. Neste sentido, este artigo apresenta um mapeamento da existência desse profissional na rede pública estadual brasileira, além de uma discussão crítica sobre a especificidade do trabalho do orientador educacional, apontando para a necessidade de sua presença em todas as escolas da rede escolar brasileira.
\end{abstract}

Palavras-chave: Orientação Educacional; Orientador Educacional; Pedagogo

\section{THE EDUCATIONAL COUNSELOR IN BRASIL}

ABSTRACT: Historically, educational counseling is one of the activities carried out by pedagogues. This professional goes by varied denominations and performs equally varied activities in different schools and in the different states of Brazil. Such diversity deprives pedagogues of the characteristics and the true dimension of their professional tasks and creates a conflict with the various roles played by different education professionals. This paper maps the presence of pedagogues in Brazilian public schools and discusses the specificity of the educational counselor's work critically. It also shows the need of pedagogues in all Brazilian schools.

Keywords: Educational Counseling; Educational Counselor; Pedagogue

\footnotetext{
* Doutora em Educação pela Faculdade de Educação da UNICAMP e profesora da Faculdade de Educação da PUC-Campinas. E-mail: miriam@newslink.com.br

* Aluna do $6^{\circ}$ período do curso de Pedagogia da PUC-Campinas e orientanda de Iniciação Científica.

** Aluna do $8^{\circ}$ período do curso de Pedagogia da PUC-Campinas e orientanda de Iniciação Científica.
} 


\section{INTRODUĈุ̃O}

Por acreditar que seja possível a construção de uma Orientação Educacional vista como uma prática social ampla, a serviço da escola pública, tão repleta de desafios, é que desenvolvemos a presente pesquisa. Sempre nos inquietaram as dúvidas referentes à não-existência da orientação educacional nas escolas públicas do estado de São Paulo. Em nossa realidade, pensávamos nos porquês de a escola particular poder contar com tal profissional e a escola pública, não. Por que uma existência restrita a determinada camada social, que freqüenta a escola particular? Se o profissional orientador educacional fosse desnecessário como membro integrante da equipe pedagógica da escola, por quais razões a escola particular o manteria? Se essa situação é existente em São Paulo, como seria nos outros estados brasileiros? Essas inquietações nos motivaram a desenvolver a presente pesquisa e, para isso, recorremos, primeiramente, ao resgate histórico da função do orientador educacional e, posteriormente, ao mapeamento da existência de tal profissional nos diferentes estados brasileiros.

Historicamente, os cursos de Pedagogia têm formado profissionais para o exercício de funções ligadas à gestão educacional: administradores escolares, orientadores educacionais e supervisores de ensino. Tais profissionais, muitas vezes, ao mudarem de estado, encontram realidades profissionais diferentes e, em muitas delas, o seu campo profissional apresenta-se restrito. $\mathrm{O}$ diretor de escola, por exemplo, no estado de São Paulo, é escolhido mediante concurso público e, para isso, deverá ser pedagogo, ao passo que no Mato Grosso, a escolha é feita pela administração superior, uma vez que é cargo de confiança que pode ser ocupado por um professor, que nem ao menos precisa ter o título de pedagogo.

A realidade profissional diversa que o administrador escolar encontra também acontece com o orientador educacional. Em alguns estados brasileiros, na rede escolar estadual, o orientador faz parte da equipe de gestão escolar, como acontece com o Distrito Federal e os estados de Rio de Janeiro, Paraná, Rio Grande do Sul, por exemplo, enquanto que, em outros, tal profissional não existe.

A existência e a permanência do orientador educacional na rede escolar é bastante questionada e o enfoque dado às atividades que desempenha passa por modificações, de acordo com os estados, em suas regulamentações.

Talvez pelos "paradigmas herdados", hoje seja necessário que se construam parâmetros para a atuação desse profissional numa perspecti- 
va crítica e emancipatória. Não há dúvida de que o orientador educacional seja necessário ao processo educacional. Existe uma ligação entre tal prática e a própria educação, uma vez que na raiz da palavra educação encontrase "orientar, guiar, conduzir o aluno". Em outras palavras, o papel do orientador educacional deve ser o de mediador entre o aluno, as situações de caráter didático-pedagógico e as situações socioculturais. Além disso, a razão de ser da escola e da própria educação é o aluno, centro dos estudos da orientação educacional.

A partir das considerações acima apontadas, este trabalho tem como objetivo apresentar pontos para discussão, com a finalidade de levar o leitor à percepção da importância da presença do profissional orientador educacional em todas as escolas de educação básica do país.

Para nortear a reflexão, apresentamos, a seguir, dados históricos sobre a questão e, posteriormente, apontamos para cinco áreas que podem ser beneficiadas com o trabalho do profissional orientador educacional: o aluno, a escola, a família, a comunidade e a sociedade.

\section{DADOS HISTÓRICOS SOBRE A ORIENTAC̣ÃO EDUCACIONAL}

Segundo Pimenta (1988), a orientação educacional teve origem, aproximadamente, em 1930, a partir da orientação profissional que se fazia nos EUA. No Brasil, a orientação educacional mostrou-se válida na ordenação da sociedade brasileira em mudança na década de 1940 e incluía a ajuda ao adolescente em suas escolhas profissionais. A autora mostra que a primeira menção a cargos de orientador nas escolas estaduais se deu pelo Decreto n. 17.698, de 1947, referente às Escolas Técnicas e Industriais.

As Leis Orgânicas do Ensino referentes ao período de 1942 a 1946 fazem alusão à Orientação Educacional. Nesta época, não havia cursos especiais de orientação educacional, o que levou ao preenchimento dos cargos pelos chamados "técnicos de educação", muitas vezes selecionados por critérios duvidosos.

A autora menciona ainda que, até 1958, São Paulo contava com cinco faculdades que ministravam o curso superior de orientação educacional, tendo sido, o primeiro deles, o curso criado pela PUC-Campinas, em 1945.

Em 1958, o MEC regulamentou provisoriamente o exercício da função e o registro de Orientador Educacional, pela Portaria n. 105, de março de 1958, tendo ela permanecido provisória até 1961, quando a LDB 4.024 veio regulamentar a formação do Orientador Educacional. 
A Lei 5.564, de 21/12/68, demonstra, assim como a LDB em vigor naquela época, preocupação com a formação integral do adolescente, embora traga orientações também referentes ao ensino primário, como era naquela época designado o ensino fundamental.

Art. $1^{\circ}$ A Orientação Educacional se destina a assistir ao educando, individualmente ou em grupo, no âmbito das escolas e sistemas escolares de nível médio e primário, visando o desenvolvimento integral e harmonioso de sua personalidade, ordenando e integrando os elementos que exercem influência em sua formação e preparando-o para o exercício das opções básicas.

A LDB que veio a seguir, a 5.692/71, diz, no artigo 10: "será instituída obrigatoriamente a Orientação Educacional, incluindo aconselhamento vocacional em cooperação com os professores, a família e a comunidade".

Segundo Pimenta (1981), a LDB dá um sentido novo ao ensino de $1^{\circ}$ e $2^{\circ}$ graus: sondagem de aptidão e profissionalizante, por isso, a Orientação Educacional deveria se ocupar de aconselhamento vocacional. "Assim, o que era apenas uma área da Orientação Educacional passa a ser confundida com a própria” (p. 99).

Para atender às exigências da legislação, o Decreto 72.846 de 1973 veio a regulamentar a Lei 5.564, de 1968, por meio de onze artigos, mantendo, porém, o artigo $1^{\circ}$ da Lei 5.564, apenas substituindo as expressões "no âmbito das escolas e sistemas escolares de nível médio e primário" por "no âmbito do ensino de $1^{\circ}$ e $2^{\circ}$ graus." (PIMENTA, 1981, p. 101).

Uma leitura crítica da legislação e dos contextos sociais em que foram promulgadas pode nos levar a entender que a orientação educacional no Brasil tem cumprido os papéis que dela eram esperados; muitas vezes a favor do sistema excludente e poucas vezes carregada de ousadia no sentido da emancipação das camadas populares. Isso se deve, principalmente, ao fato de estar atrelada às políticas educacionais vigentes nos diferentes momentos históricos.

Os referenciais teóricos confusos e obscuros têm contribuído para a colocação da função do orientador no "baú" do esquecimento. Esteve ligada às relações de poder dentro da escola, às funções de comando, contribuindo para a divisão social do trabalho reproduzida dentro da escola.

Prevendo conflitos, alguns autores já alertavam para a necessidade de definição das funções e campos de atuação do orientador educacional, como Brandão (1982) e Melo (1994), que tentavam mostrar a 
importância da construção de um elo entre a prática do orientador educacional e as variações da sociedade e cultura brasileiras, das ciências humanas e das teorias da educação.

Pode-se dizer que o campo de atuação do orientador educacional era, inicialmente, apenas e tão somente focalizar o atendimento ao aluno, aos seus "problemas", à sua família, aos seus "desajustes" escolares, etc., pouco ou quase nada voltado à autonomia do aluno e à sua contextualização como cidadão. Depois, voltou-se à prestação de serviços, mas sempre com o objetivo de ajustamento ou prevenção.

Na década de 1970, falou-se muito sobre a falta de compromisso da escola e de sua equipe pedagógica. Grinspun (2003, p. 20) diz que, nesse período "tenta-se resgatar a importância da escolaridade para as estratégias de vida das camadas populares, chamando a atenção para a estrutura interna da escola como um dado significativo para o desempenho dos alunos. A Orientação estava dentro da escola e não se deu conta do seu papel".

Balestro (2005, p. 19) complementa a autora dizendo que "os orientadores educacionais deixaram a banda passar sem dar a sua contribuição, isto é, sem fazer parte dela. Eles ficaram em cima do muro e calados. Perderam um espaço para demarcar o seu território na educação e a função social da profissão de OE”.

Por tais motivos, a Orientação Educacional começa a ser questionada a partir de 1980. Assim, os pressupostos teóricos começam a ser repensados e rediscutidos. O orientador começa a participar de todos os momentos da escola, discutindo questões curriculares, como objetivos, procedimentos, critérios de avaliação, metodologias de ensino, demonstrando sua preocupação com os alunos e o processo de aprendizagem. Os cursos de reciclagem que foram oferecidos aos orientadores contribuíram para que a discussão fosse mais ampla, envolvendo as práticas, os valores que a norteavam, a realidade dos alunos, assim como o mundo do trabalho.

Millet (1987, p. 43), numa atuação ousada para a época e incompreendida pelos profissionais da educação da escola onde ela mesma trabalhava, já apresentou, quase vinte anos atrás, uma mudança de enfoque no trabalho do orientador educacional. "É necessário pensar junto com os alunos sobre o ambiente que os circunda e as relações que estabelecem com esse ambiente, para que, tomando consciência da expropriação a que são submetidos, sintam-se fortalecidos para lutar por seus direitos de cidadãos." 
Segundo a autora, indisciplina, agressividade, desinteresse, dificuldades de aprendizagem (queixas mais comuns dos professores) não podem e não devem ser tratadas isoladamente e, sim, a partir de um estudo das relações "professor-aluno, aluno-conteúdo, aluno-aluno, alunoestatutos escolares, aluno-comunidade, professor-comunidade" (p. 43). Pela apresentação de um relato de experiência, a autora conclui alertando para o caráter político da atuação do orientador educacional que "ultrapassa os limites dos muros da escola" e se envolve com a comunidade.

Origina-se aí uma nova visão de orientação educacional.

A orientação, hoje, está mobilizada com outros fatores que não apenas e unicamente cuidar e ajudar os 'alunos com problemas'. Há, portanto, necessidade de nos inserirmos em uma nova abordagem de Orientação, voltada para a 'construção' de um cidadão que esteja mais comprometido com seu tempo e sua gente. Desloca-se, significativamente, o 'onde chegar', neste momento da Orientação Educacional, em termos do trabalho com os alunos. Pretendese trabalhar com o aluno no desenvolvimento do seu processo de cidadania, trabalhando a subjetividade e a intersubjetividade, obtidas através do diálogo nas relações estabelecidas. (GRINSPUN, 1994, p. 13)

Villon (1994) diz que o trabalho do orientador educacional deve ser o de propiciar a aproximação entre a escola e a comunidade, desvelando os papéis e a influência que diversas instituições, tais como clubes, indústrias, comércios locais, associações, clubes, etc. exercem na comunidade. Preconiza a liberdade de extrapolar o espaço escolar indo rumo à comunidade escolar. A autora evidencia, desta forma, que o campo de atuação do orientador educacional não se limita à microestrutura escolar.

Assis (1994) apresenta a importância do papel do orientador educacional como co-responsável pela aprendizagem dos alunos. Questiona as práticas docentes envolvendo os aspectos didático-pedagógicos, tais como metodologia, avaliação, relação professor-aluno, objetivos, conteúdos, e mostra a necessidade de que os docentes conheçam e reflitam sobre o real significado da existência da escola e sua função social. Apresenta o papel do orientador educacional numa dimensão bastante ampla e fala também da escola como locus privilegiado de participação. Questiona a formação profissional, mostrando que há necessidade do domínio de conteúdos necessários a uma nova atuação. A autora diz que a Filosofia ajuda o orientador educacional no sentido da práxis pedagógica e acrescenta: "Outros conhecimentos devem fundamentar a prática do orientador educacional, tais como: Psicologia, Sociologia, História da Educação e História do Brasil (até nossos dias), além de outros, oriundos da Antropologia, Ciências Políticas, Metodologia e Pesquisa em uma abordagem qualitativa". (p. 137) 
Placco (1994, p. 30) conceitua a orientação educacional como um processo social desencadeado dentro da escola, mobilizando todos os educadores que nela atuam - especialmente os professores - para que, na formação desse homem coletivo, auxiliem cada aluno a se construir, a identificar o processo de escolha por que passam, os fatores socioeconômico-políticoideológicos e éticos que o permeiam e os mecanismos por meio dos quais ele possa superar a alienação proveniente de nossa organização social, tornandose, assim, um elemento consciente e atuante dentro da organização social, contribuindo para sua transformação.

Esse período referente à década de 1980, que Grinspun (1994) chama de "questionador", foi marcado por estudos, congressos, lutas sindicais, que, articuladamente, transformaram-se em grandes conquistas para os orientadores educacionais.

A FENOE - Federação Nacional dos Orientadores Educacionais - teve importante papel em defesa dos orientadores educacionais, sendo extinta na década de 90, o que levou ao enfraquecimento da categoria profissional que representava. A AOERGS - Associação dos Orientadores Educacionais do Rio Grande do Sul - tem contribuído significativamente com a categoria profissional dos Orientadores Educacionais, sendo responsável pela publicação Prospectiva, que traz matéria sobre orientação no Brasil.

Grinspun (1994) diz que o período "orientador", a partir da década de 90, foi cheio de incertezas e questionamentos. Não se sabia se a nova LDB traria ou não menções ao Orientador Educacional em seu texto.

Tais incertezas foram dizimadas com a publicação da Lei de Diretrizes e Bases da Educação Nacional (LDB 9394/96), que em seu artigo 64, diz:

A formação de profissionais de educação para administração, planejamento, inspeção, supervisão e orientação educacional para a educação básica, será feita em cursos de graduação em pedagogia ou em nível de pós-graduação, a critério da instituição de ensino, garantida, nesta formação, a base comum nacional. (LDB 9394/96, grifo nosso)

Embora pareça reconhecida a sua importância pela LDB, ao mesmo tempo deixa em aberto a formação profissional do orientador. Isso pode levar os cursos de Pedagogia a deixarem de formar o orientador educacional, relegando para a pós-graduação tal tarefa.

Inicia-se um novo período nos anos 2000. O ensino, de uma maneira geral, e, em especial, o ensino público, está caminhando aos 
“trancos e barrancos". Globalmente, o país está mal no cenário educacional. É comum vermos reportagens mostrando o baixo nível de aprendizagem dos alunos nas escolas brasileiras. Isso mostra que a equipe escolar precisa ser rearticulada. No entanto, as Diretrizes Curriculares Nacionais para o curso de graduação em Pedagogia, Licenciatura, em Parecer aprovado em 13/12/2005, reduzem a orientação educacional à área de serviços e apoio escolar, o que significa mais um passo para a extinção total desta função. Incoerentemente, o artigo $5^{\circ}$ menciona que o egresso do curso de Pedagogia deverá estar apto para uma série de tarefas possíveis apenas a partir de um trabalho integrado com outros profissionais da educação.

II compreender, cuidar e educar crianças de zero a cinco anos, de forma a contribuir para o seu desenvolvimento nas dimensões, entre outras, física, psicológica, intelectual, social;

VII promover e facilitar relações de cooperação entre a instituição educativa, a família e a comunidade;

XIV realizar pesquisas que proporcionem conhecimentos, entre outros: sobre alunos e alunas e a realidade sociocultural em que estes desenvolvem suas experiências não-escolares; sobre processos de ensinar e de aprender, em diferentes meios ambiental-ecológicos; sobre propostas curriculares e sobre organização do trabalho educativo e práticas pedagógicas.

É interessante observar que as tarefas apontadas são apenas algumas que podem ser realizadas pelo orientador educacional, em trabalho articulado com o gestor e o coordenador pedagógico.

Não resta dúvida de que a gestão escolar que visa à emancipação necessita de apoio e trabalho conjunto de diferentes profissionais da educação, em suas diferentes frentes de atuação, que não podem ser relegadas a segundo plano. Toda escola realiza um trabalho pedagógico composto por situações de caráter burocrático-administrativo e situações de caráter pedagógico-administrativo. O primeiro grupo envolve, prioritariamente, a documentação escolar. Envolve, ainda, a organização e a divisão do trabalho propriamente dito: a divisão de funções, a determinação de horários a serem cumpridos pelos funcionários e horários de funcionamento dos diferentes setores; a divisão do pessoal nos diversos turnos e setores, abertura e fechamento de portões, merenda escolar, etc. Toda essa parte é importante porque, sem ela, a escola não pode caminhar. Ela representa a estrutura indispensável para que seja possível a realização do ato educativo.

Não menos importantes são as situações de caráter pedagógicoadministrativo. Envolvem todas as iniciativas que a escola deve ter para que o ensino e a aprendizagem ocorram. Aliás, este é o coração do traba- 
lho pedagógico. Aí destacam-se duas ordens de necessidades diferentes: uma ligada ao professor e outra ligada ao aluno.

Mesmo reconhecendo a imprescindibilidade da tecnologia da informação, o professor não pode ser descartado. Porém, para fazer frente a todos os avanços da sociedade, há necessidade de um novo professor, mais atuante, mais atualizado, com novas competências. Destacase, então, que a escola precisa ter um profissional que coordene todo o trabalho docente. E este é o profissional conhecido como "coordenador pedagógico", mais especificamente, o professor coordenador, no estado de São Paulo. Este profissional é aquele encarregado de cuidar da atualização docente em serviço, de fornecer condições estruturais e materiais para que o trabalho docente se desenvolva, de divulgar obras existentes na biblioteca para os professores, organizar as reuniões pedagógicas, cuidar da interdisciplinaridade, enfim, proporcionar ao professor meios para que possa desenvolver o seu trabalho da melhor maneira possível.

O aluno, por sua vez, é a razão de ser da escola. Para colaborar com o aluno e com as suas necessidades, a escola precisa contar com o trabalho do orientador educacional. Esse é o profissional que trabalha diretamente com o aluno e se preocupa com a sua formação pessoal. A ele cabe desenvolver propostas que elevem o nível cultural do aluno e tudo fazer para que o ambiente escolar seja o melhor possível.

$\mathrm{O}$ orientador educacional diferencia-se do coordenador pedagógico, do professor e do diretor. $\mathrm{O}$ diretor ou gestor administra a escola como um todo; o professor cuida da especificidade de sua área do conhecimento; o coordenador fornece condições para que o docente realize a sua função da maneira mais satisfatória possível; e o orientador educacional cuida da formação de seu aluno, para a escola e para a vida.

Como já vimos, o estado de São Paulo não possui esse profissional em sua equipe de gestão. Infelizmente, as marcas do passado, em que o orientador educacional exercia uma função de caráter comportamentalista, ligada aos desajustes escolares, o que o confundia com o psicólogo escolar, deixou raízes profundas e difíceis de remover. Porém, outros estados contam com esse profissional e demonstram que a sua função, na sociedade contemporânea, além de necessária, é imprescindível.

\section{CONTRIBUIÇÕES PARA UM REPENSAR SOBRE A ORIENTAÇÃO EDUCACIONAL}

Como partícipe da equipe de gestão, a orientação educacional pode se desenvolver em cinco áreas: o aluno, a escola, a família, a comunidade e a sociedade. 


\section{0 orientador educacional e os alunos:}

\section{a criação de espaços de participação social e exercício da cidadania}

A visão contemporânea de orientação educacional aponta para o aluno como centro da ação pedagógica, cabendo ao orientador atender a todos os alunos em suas solicitações e expectativas, não restringindo a sua atenção apenas aos alunos que apresentam problemas disciplinares ou dificuldades de aprendizagem.

Mediador entre o aluno e o meio social, o orientador discute problemas atuais, que fazem parte do contexto sociopolítico, econômico e cultural em que vivemos. Assim, por meio da problematização, pode levar o aluno ao estabelecimento de relações e ao desenvolvimento da consciência crítica.

Para poder exercer a contento a sua função, o orientador precisa compreender o desenvolvimento cognitivo do aluno, sua afetividade, emoções, sentimentos, valores, atitudes. Além disso, cabe a ele promover, entre os alunos, atividades de discussão e informação sobre o mundo do trabalho, assessorando-os no que se refere a assuntos que dizem respeito a escolhas.

Todas as relações que se estabelecem no cotidiano escolar, em especial o relacionamento com os colegas, podem receber inúmeras contribuições do profissional orientador educacional.

\section{0 orientador educacional e a escola:}

\section{a participação nos momentos coletivos}

Como membro do corpo gestor da escola, cabe ao orientador educacional participar da construção coletiva de caminhos para a criação de condições facilitadoras e desejáveis ao bom desenvolvimento do trabalho pedagógico. É um profissional que participa de todos os momentos coletivos da escola, na definição de seus rumos, na elaboração e na avaliação de sua proposta pedagógica, nas reuniões do Conselho de Classe, oferecendo subsídios para uma melhor avaliação do processo educacional. Desta forma, é necessária a discussão sobre a natureza da vida escolar, em que todos os integrantes da equipe pedagógica escolar "questionem criticamente o currículo existente na escola, o currículo oculto, o aparelho político em todos os níveis, a forma e o conteúdo dos textos escolares e as condições de trabalho que caracterizam escolas específicas". (GIROUX, 1987, p. 48)

O orientador, aliado aos demais profissionais da escola e a outros pedagogos, pode contribuir muito para a organização e a dina- 
mização do processo educativo. É o que dizem Giacaglia e Penteado (2002, p. 15): "participando do planejamento e da caracterização da escola e da comunidade, o orientador educacional poderá contribuir, significativamente, para decisões que se referem ao processo educativo como um todo".

Cabe a ele integrar todos os segmentos que compõem a comunidade escolar: direção, equipe técnica, professores, alunos, funcionários e famílias, visando à construção de um espaço educativo ético e solidário.

Em que pesem as contribuições do profissional orientador educacional ao processo educativo, muitas escolas, notadamente na rede escolar estadual paulista, não têm mais esse profissional na equipe, o que significa que outro profissional está acumulando as suas funções. Normalmente esse profissional é o coordenador pedagógico, que, além de cumprir a sua extensa função junto aos professores, associa a ela a função do orientador, resultando numa inadequação das duas.

\section{0 orientador educacional e a família:}

\section{a criação de ambientes socioeducativos}

O orientador educacional é o profissional encarregado da articulação entre escola e família. Assim, cabe a ele a tarefa de contribuir para a aproximação entre as duas, planejando momentos culturais em que a família possa estar presente, junto com seus filhos, na escola. Cabe também ao orientador educacional a tarefa de servir de elo entre a situação escolar do aluno e a família, sempre visando a contribuir para que o aluno possa aprender significativamente. A perspectiva de orientação educacional que consideramos válida não se equipara ao trabalho do psicólogo escolar, que tem dimensão terapêutica. O papel do orientador com relação à família não é apontar desajustes ou procurar os pais apenas para tecer longas reclamações sobre o comportamento do filho e, sim, procurar caminhos, junto com a família, para que o espaço escolar seja favorável ao aluno. Não cabe ao orientador a tarefa de diagnosticar problemas e/ou dificuldades emocionais ou psicológicas e, sim, que volte seu trabalho para os aspectos saudáveis dos alunos.

\section{0 orientador educacional e a comunidade: o conhecimento do contexto local}

Compreender o modo de vida, os interesses, as aspirações, as necessidades, as conquistas da comunidade é muito importante. Só assim será possível o apoio da escola na luta da comunidade por melhores 
condições de vida. Neste sentido, pode-se apontar que uma das tarefas do orientador educacional é o conhecimento da comunidade e das situações que facilitam sua vida, bem como as que a dificultam.

Como pólo cultural, cabe à escola e, especificamente, ao orientador educacional elevar o nível cultural dos membros da comunidade, propiciar debates sobre temas de interesse, bem como de alunos, pais, professores, envolvendo questões presentes no dia-a-dia. É fundamental que se estabeleça um clima de constante diálogo entre ambas, uma vez que a escola deve estar aberta à comunidade à qual pertence.

Como estratégia que pode colaborar para o bom andamento do trabalho educativo, podemos citar a abertura da escola à comunidade, que nem sempre é feita de forma tranqüila, com afirma Vasconcellos (2002, p. 63):

Alguns diretores tratam os equipamentos da escola como se fossem objetos pessoais, propriedades privadas; outros, ao contrário, estabelecem relações de parceria com a comunidade e, com isto, não só passam a contar com ela como elemento de apoio para as mudanças, como ainda obtêm diminuição do vandalismo, da violência; os alunos se sentem acolhidos, experimentam a escola como território aliado. Queremos deixar claro que estamos nos referindo à abertura tanto no que diz respeito às instalações e equipamentos, quanto, num sentido mais sutil, de se deixar sensibilizar pelas exigências colocadas pela sociedade.

\section{0 orientador educacional e a sociedade:}

\section{a participação em lutas maiores}

Da mesma forma que se dá o trabalho do orientador educacional no que se refere à comunidade, assim também o é no que se refere à sociedade. $\mathrm{O}$ orientador educacional é o profissional da escola que, não tendo um currículo a seguir, pode se organizar para trazer aos alunos os fatos sociais marcantes que nos envolvem, bem como propor a participação em lutas maiores. A escola não pode silenciar face às grandes questões que a mídia veicula diariamente. Discutir a corrupção, os atos de terrorismo, a violência urbana e outras situações presentes na sociedade brasileira e na mundial serão de grande utilidade para os demais componentes curriculares. De modo análogo, não só deve o orientador educacional levar a sociedade para a escola, mas, também, como uma via de mão dupla, levar a escola, suas conquistas e dificuldades para a sociedade.

\section{O ORIENTADOR EDUCACIONAL E OS PRINCÍPIOS ÉTICOS}

É extremamente válido lembrar que o trabalho do orientador educacional, assim como o trabalho pedagógico de modo geral, precisa estar revestido pelo comportamento ético. 
Em todos os campos em que o orientador educacional atua, ele estará sempre em contato com algumas informações que precisam ser sigilosas. Isso acontece, por exemplo, quando o profissional conversa com alunos e seus familiares, momentos em que, muitas vezes, toma conhecimento de situações complexas e delicadas. O bom senso, o sigilo e o cuidado na emissão de juízos de valor podem favorecer o trabalho do orientador. A confiança na pessoa do orientador é fundamental para o êxito de seu trabalho.

Um fato que ocorre com muita freqüência é a solicitação de informações sobre os alunos pelos professores. Neste caso, o orientador precisa tomar muito cuidado, fornecendo apenas informações que sejam relevantes, pois, como dizem Giacaglia e Penteado (2002, p. 10),

há que se considerar razões de natureza psicológica para a não-divulgação dos dados. Trata-se do "efeito Rosenthal" ou "profecia auto-realizável”, segundo a qual, quando um professor desenvolve expectativas de que um aluno ou grupo de alunos irá ter insucesso escolar, tais expectativas podem se transformar, inconscientemente, por parte do professor, em fator ou causa do respectivo fracasso daqueles alunos.

Por acreditar na necessidade do orientador educacional dentro da escola, desenvolvemos a presente pesquisa com a finalidade de identificar quais estados mantêm esse profissional em seus quadros para, num segundo momento, buscar sinais indicativos da necessidade desse profissional nas escolas públicas brasileiras.

\section{A PESQUISA REALIZADA}

A pesquisa partiu de um levantamento, tipo survey, que é a pesquisa que busca informação diretamente com um grupo de interesse a respeito dos dados que se deseja obter. Trata-se de caracterizar dada população, não tendo nenhuma intenção de se alterar o fenômeno.

O estudo exploratório (survey) é muito comum em pesquisa e pode incluir questionários, entrevistas, surveys por telefone e outras formas de obtenção de dados. No caso da presente pesquisa, utilizou-se, na etapa final, de surveys por telefone.

Segundo Triviños (1987, p. 109),

os estudos exploratórios permitem ao investigador aumentar sua experiência em torno de determinado problema. O pesquisador parte de uma hipótese e aprofunda seu estudo nos limites de uma realidade específica, buscando antecedentes, maior conhecimento para, em seguida, planejar uma pesquisa descritiva ou do tipo experimental. Outras vezes, deseja delimitar ou manejar com maior segurança uma teoria cujo enunciado resulta demasiado amplo 
para os objetivos da pesquisa que tem em mente realizar. Pode ocorrer também que o investigador, baseado numa teoria, precise elaborar um instrumento, uma escala de opinião, por exemplo, que cogita num estudo descritivo que está planejando. Então o pesquisador planeja um estudo exploratório para encontrar os elementos necessários que lhe permitam, em contato com determinada população, obter os resultados que deseja. Um estudo exploratório, por outro lado, pode servir para levantar possíveis problemas de pesquisa.

Nesta perspectiva, buscamos, inicialmente, fazer um mapeamento sobre a existência da Orientação Educacional nos diferentes estados brasileiros. Para isso, dividimos a busca por regiões:

Região Norte: Acre, Amapá, Amazonas, Pará, Rondônia, Roraima, Tocantins. Região Nordeste: Maranhão, Piauí, Ceará, Rio Grande do Norte, Paraíba, Pernambuco, Alagoas, Sergipe, Bahia.

Região Centro-Oeste: Mato Grosso, Mato Grosso do Sul, Goiás, Distrito Federal.

Região Sul: Rio Grande do Sul, Santa Catarina, Paraná

Região Sudeste: São Paulo, Rio de Janeiro, Espírito Santo, Minas Gerais.

Foram feitas pesquisas junto ao MEC e outros sites relacionados à educação, como o Conselho Nacional de Educação, Conselho Estadual de Educação, INEP, CONSED, além das Secretarias de Estado da Educação.

Esperava-se que os dados iniciais, ou seja, o levantamento dos estados que possuem o orientador educacional em suas redes escolares estaduais, fosse a etapa mais fácil de ser realizada, uma vez que pensávamos que o MEC possuísse tais dados ou que estivessem disponíveis online. No entanto, isso não ocorreu e, então, tentamos efetuar o contato de três formas diferentes: e-mail, carta e telefone.

A tentativa de conseguir obter os dados via e-mail foi totalmente infrutífera. Apenas um estado respondeu ao nosso contato, com atraso de dois meses. A tentativa número dois, ou seja, via carta, também mostrouse inadequada. Obtivemos apenas duas respostas. Assim, não nos restou outra alternativa a não ser obter os dados via telefone. A partir do site do CONSED, obtivemos os números dos telefones atualizados e efetuamos as ligações da PUC-Campinas.

Além de mapear a existência do orientador nos diferentes estados, também identificamos quais as redes escolares (estadual, municipal ou particular) que atendem os diferentes níveis de ensino (educação infantil, ensino fundamental e médio) nos estados que possuem orientação educacional. 


\section{RESULTADOS}

Dos 26 estados mais o Distrito Federal, 13 possuem o orientador educacional na sua rede escolar estadual, como mostra o mapa a seguir:

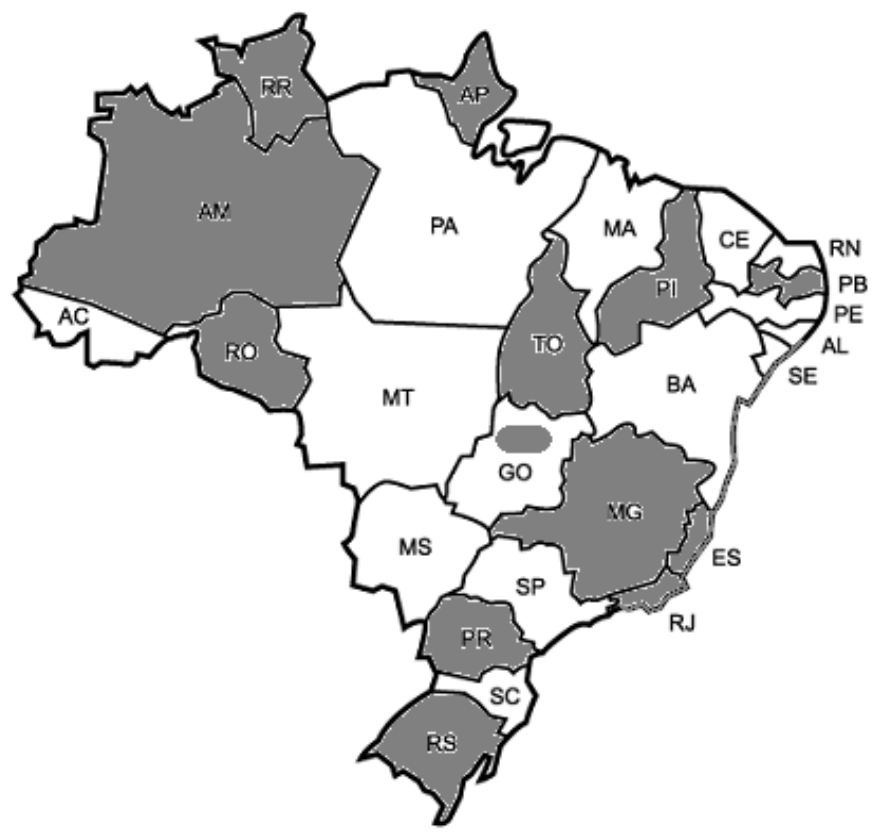

\section{Discussão}

A região Norte (Acre, Amapá, Amazonas, Pará, Rondônia, Roraima, Tocantins) possui 7 estados, dos quais 5 possuem o profissional orientador educacional em suas redes escolares: Amazonas, Roraima, Rondônia e Amapá.

No Amapá, existem 424 escolas estaduais de educação básica, de um total de 812. A educação infantil (creche) é atendida por 26 escolas da rede particular e por 16 da rede municipal, existindo apenas 2 escolas estaduais. A pré-escola é atendida prioritariamente pela rede municipal, seguida pela rede estadual. O ensino fundamental e médio são atendidos, prioritariamente, pela rede estadual.

No Amazonas, existem 527 escolas estaduais de educação básica, de um total de 5156. A rede municipal atende, quase que exclusivamente, a rede escolar, com um total de 4341 escolas. A rede estadual atende o segmento de $5^{\mathrm{a}}$ a $8^{\mathrm{a}}$ e ensino médio.

Em Rondônia existem 369 escolas estaduais de educação básica, de um total de 2292. A rede municipal atende, quase que exclusivamente, 
a rede escolar, com um total de 1719 escolas. A rede estadual atende o segmento de $5^{a}$ a $8^{a}$ e ensino médio.

No estado de Roraima, existem 588 escolas estaduais de educação básica, de um total de 789. A educação infantil (creche) é atendida prioritariamente pela rede municipal. A pré-escola é atendida prioritariamente pela rede estadual, seguida pela rede municipal. Os ensinos fundamental e médio são atendidos, prioritariamente, pela rede estadual.

No Estado de Tocantins existem apenas 524 escolas estaduais de educação básica, de um total de 2267. A rede municipal é a que atende, prioritariamente, os níveis de ensino referentes à educação infantil e ao ensino fundamental $1^{a}$ a $4^{a}$ série. A rede estadual tem prioridade apenas no ensino fundamental $5^{\mathrm{a}}$ a $8^{\mathrm{a}}$ e ensino médio. É interessante observar que é essa região que mais possui, em seus quadros, o profissional orientador educacional.

A região Nordeste possui 9 estados (Maranhão, Piauí, Ceará, Rio Grande do Norte, Paraíba, Pernambuco, Alagoas, Sergipe, Bahia), dos quais apenas Piauí e Paraíba possuem o orientador educacional em seus quadros de profissionais da educação na rede estadual.

O Estado do Piauí possui 886 escolas de educação básica na rede estadual, de um total de 7966. A rede municipal é a que atende, prioritariamente, os níveis de ensino referentes à educação infantil e ensino fundamental $1^{\mathrm{a}}$ a $4^{\mathrm{a}}$ série. A rede estadual tem prioridade apenas no ensino fundamental $5^{\mathrm{a}}$ a $8^{\mathrm{a}}$ e ensino médio.

O estado da Paraíba possui 1220 escolas de educação básica na rede estadual, de um total de 7257. A rede municipal atende, prioritariamente, os níveis de ensino referentes à educação infantil e ensino fundamental $1^{\mathrm{a}}$ a $4^{\mathrm{a}}$ série. A rede estadual tem prioridade apenas no ensino fundamental $5^{\mathrm{a}}$ a $8^{\mathrm{a}}$ e ensino médio.

A região Centro-Oeste (Mato Grosso, Mato Grosso do Sul, Goiás, Distrito Federal) possui 3 estados, além do Distrito Federal, sendo que apenas este último possui o orientador educacional em sua rede escolar estadual.

No Distrito Federal existem 1046 escolas de educação básica, sendo 610 pertencentes à rede estadual. As demais são atendidas pela rede particular. Não existe rede municipal.

A região sul (Rio Grande do Sul, Santa Catarina, Paraná) possui 3 estados, dos quais 2 possuem o orientador educacional em seus quadros de profissionais da educação na rede estadual: Rio Grande do Sul e Paraná. 
No Rio Grande do Sul, existem 3002 escolas de educação básica, na rede estadual escolar, de um total de 10626. A rede municipal atende, prioritariamente, os níveis de ensino referentes à educação infantil e ensino fundamental $1^{\mathrm{a}}$ a $4^{\mathrm{a}}$ série. A rede estadual tem prioridade apenas no ensino fundamental $5^{\mathrm{a}}$ a $8^{\mathrm{a}}$ e ensino médio.

No Paraná, existem 2065 escolas de educação básica pertencentes à rede estadual, de um total de 9349 escolas. A rede municipal atende, prioritariamente, os níveis de ensino referentes à educação infantil e ensino fundamental $1^{\mathrm{a}}$ a $4^{\mathrm{a}}$ série. A rede estadual tem prioridade apenas no ensino fundamental $5^{\mathrm{a}}$ a $8^{\mathrm{a}}$ e ensino médio.

A região Sudeste (São Paulo, Rio de Janeiro, Espírito Santo, Minas Gerais) possui 4 estados, dos quais 3 possuem o orientador educacional em seus quadros de profissionais da educação na rede estadual: Rio de Janeiro, Espírito Santo e Minas Gerais.

No Rio de Janeiro, existem 1869 escolas de educação básica, na rede estadual escolar, de um total de 10409. A rede municipal atende, prioritariamente, os níveis de ensino referentes à educação infantil e ensino fundamental $1^{\mathrm{a}}$ a $4^{\mathrm{a}}$ série. A rede estadual tem prioridade apenas no ensino fundamental $5^{\mathrm{a}}$ a $8^{\mathrm{a}}$ e ensino médio.

No Espírito Santo, existem 1246 escolas de educação básica, na rede estadual escolar, de um total de 4139. A rede municipal é a que atende, prioritariamente, os níveis de ensino referentes à educação infantil e ao ensino fundamental $1^{\mathrm{a}}$ a $4^{\mathrm{a}}$ série. A rede estadual tem prioridade apenas no ensino fundamental $5^{\mathrm{a}}$ a $8^{\mathrm{a}}$ e ensino médio.

Em Minas Gerais, existem 3917 escolas de educação básica, na rede estadual escolar, de um total de 18098. A rede municipal atende, prioritariamente, os níveis de ensino referentes à educação infantil e ensino fundamental $1^{\mathrm{a}}$ a $4^{\mathrm{a}}$ série. A rede estadual tem prioridade apenas no ensino fundamental $5^{\mathrm{a}}$ a $8^{\mathrm{a}}$ e ensino médio. Os dados indicam que apenas o estado de São Paulo, na região Sudeste, não possui o orientador educacional em sua rede escolar estadual.

\section{CONSIDERACְ̃̃ES FINAIS}

Pela pesquisa, que envolveu o mapeamento da orientação educacional no Brasil, concluímos que dos 26 estados brasileiros mais o Distrito Federal, totalizando 27 pesquisados, 13 possuem o profissional orientador em suas redes escolares estaduais, o que corresponde a 48,14\%.

A pouca presença de Orientadores Educacionais nas escolas públicas estaduais parece estar ainda atrelada aos resquícios da imagem 
negativa da profissão, adquirida em outras épocas, nas quais os orientadores não tinham clareza de sua verdadeira função, o que abria espaço para oportunismos políticos. Hoje, porém, a função do orientador educacional liga-se à construção da cidadania, à participação política, e o seu trabalho reveste-se de uma dimensão mais pedagógica. Por isso, somos a favor da inclusão deste profissional em todas as escolas públicas brasileiras.

Não se pode afirmar que exista ligação entre a qualidade de ensino público oferecido e a presença do orientador educacional, uma vez que nenhum fator isolado pode responder pela qualidade do ensino público estadual, porém, sabemos que, se existente, este profissional estaria enriquecendo a equipe pedagógica; seria mais um profissional dentro da escola, lutando para garantir a qualidade de ensino e de desempenho dos estudantes.

Os dados oficiais sobre o desempenho de alunos não são nada animadores. No estado de São Paulo, por exemplo, dados do Saeb de 2003, referentes à avaliação nacional do Ministério da Educação, apontavam, na ocasião, que apenas $1,8 \%$ dos alunos do $3^{\circ}$ ano do ensino médio demonstraram desempenho considerado adequado em Língua Portuguesa. Mais recentemente, a Prova Brasil sobre o desempenho de estudantes aponta para resultados críticos, tanto em Língua Portuguesa, quanto em Matemática.

Embora o Saeb não tenha tratado da questão específica da influência dos profissionais não-docentes que atuam nas escolas, como o coordenador e o orientador educacional, limitando-se apenas ao gestor escolar, entendemos como muito importante a presença do profissional orientador educacional dentro de todas as escolas porque cabe a esse profissional assegurar ao aluno todas as condições favoráveis à sua aprendizagem e à formação da cidadania crítica. É importante frisar que todos os fatores que se relacionem ou possam se relacionar com o desempenho de estudantes da rede estadual brasileira devem ganhar visibilidade para que políticas públicas possam ser gestadas.

A visão de orientação de que dispomos hoje deixa para trás as funções desempenhadas por esse profissional no passado e que nem sempre colaboravam com o processo educativo. Não se trata mais de "apagar o fogo", como, historicamente, fazia o orientador educacional, chamado nas ocasiões em que havia problema a ser solucionado ou para abafar os casos de indisciplina. Nem inspetor de alunos, nem psicólogo. Hoje, além de conhecer o contexto socioeconômico e cultural da 
comunidade, bem como a realidade social mais ampla, o orientador educacional pode ser um profissional da educação encarregado de desvelar as forças e contradições presentes no cotidiano escolar e que podem interferir na aprendizagem. "A prática dos orientadores deve estar vinculada às questões pedagógicas e ao compromisso ético de contribuir na construção de uma escola democrática, reflexiva e cidadã". (BALESTRO, 2005. p. 21).

Entre os fatores apontados pelo Saeb como interferentes no desempenho dos alunos, um deles é a boa relação com a comunidade. Para responder à necessidade de integração efetiva da comunidade ao cotidiano escolar, nada melhor do que a presença do orientador educacional nas escolas. Assim, entendemos que a escola pode constituirse em espaço social e político que luta por uma sociedade mais justa, mais democrática, mais humana, a partir da influência positiva do profissional orientador educacional.

\section{REFERÊNCIAS}

ASSIS, N. Revendo o meu fazer sob uma perspectiva teórico-prática. In: GRINSPUN, M.P.S. (Org.) A prática dos orientadores educacionais. São Paulo: Cortez, 1994.

BALESTRO, M. A trajetória e a prática da orientação educacional. Revista Prospectiva n. 28, 2004/2005.

BRANDÃO,C. R. (Org.) O educador: vida e morte. Rio de Janeiro: Edições Graal, 1982.

BRASIL. Lei de Diretrizes e Bases da Educacãa Nacional. LDB 9394/96

GIACAGLIA, L. R. A. Orientação educacional na prática: princípios, técnicas, instrumentos. São Paulo: Pioneira Thomson Learning, 2002.

GRINSPUN, M.P.S.(Org.) A prática dos orientadores educacionais. São Paulo: Cortez, 1994.

GRINSPUN, M.P.S. A orientação educacional. São Paulo: Cortez, 2001.

GRINSPUN, M.P.S. Supervisão e orientação educacional. São Paulo: Cortez, 2003.

LIBÂNEO, J.C. Orientação educacional e emancipação das camadas populares: a pedagogia crítico-social dos conteúdos culturais. Prospectiva. Porto Alegre, 2 (13) 19-27, out.1984

MELO, S. M. M. Orientação educacional: do consenso ao conflito. Campinas, S.P.: Papirus, 1994.

MILET, R.M.L. Uma orientação que ultrapassa os muros da escola. Revista Ande n. 10, 1987

MOREIRA, A. F. B. e SILVA, T. T. S. Currículo, cultura e sociedade. São Paulo: Cortez, 1995.

PASCOAL, M. A orientação educacional no Brasil: uma discussão crítica. In: Poíesis pedagógica Revista do Curso de Pedagogia da Universidade Federal de Goiás. v.3, n. 3 e 4, 2005 e 2006.

PIMENTA. S. G. Uma proposta de atuação do orientador educacional na escola pública. Tese de doutorado. PUC-SP, 1985

PIMENTA. S. G. O pedagogo na escola pública. S. Paulo: Cortez, 1988.

PIMENTA. S. G. Orientação vocacional e decisão: estudo crítico da situação no Brasil. São 
Paulo: Loyola, 1981.

PLACCO, V. M. N. S. Formação e prática do educador e do orientador. Campinas, SP: Papirus, 1994.

VASCONCELLOS, C. S. Coordenação do trabalho pedagógico: do projeto político-pedagógico ao cotidiano da sala de aula. São Paulo: Libertad, 2002.

VILLON, I.G. Orientação educacional e a comunidade. In: GRINSPUN, M.P.S. (Org.) A prática dos orientadores educacionais. São Paulo: Cortez, 1994.

Recebido: $17 / 10 / 06$

Aprovado: 03/12/07

Contato:

Rua Carlos Peres Aydar, 258

Jardim das Palmeiras

Campinas - SP

BRASIL

CEP: 13101-535

E-mail: miriam@newslink.com.br 